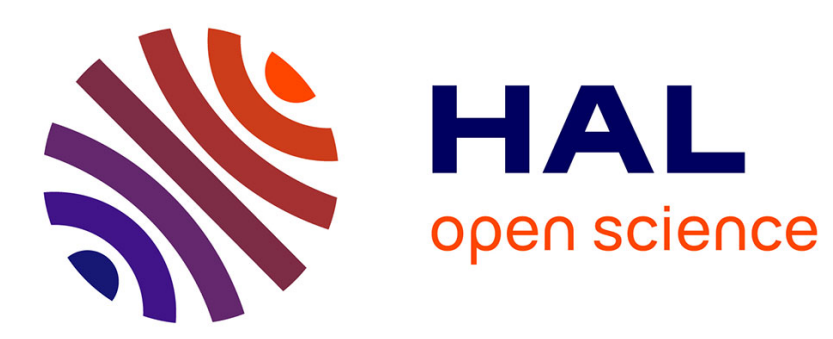

\title{
Le réseau portuaire du califat fatimide en Méditerranée (969-1171): une difficile mise en œuvre
}

David Bramoullé

\section{To cite this version:}

David Bramoullé. Le réseau portuaire du califat fatimide en Méditerranée (969-1171): une difficile mise en œuvre. Damien Coulon, Christophe Picard, Dominique Valérian. Espaces et réseaux en Méditerranée (VIe-XVIe siècle), II, Bouchène, pp.45 - 45, 2010, La formation des réseaux, 978-235676-013-5. 10.3917/bouch.coulo.2007.02.0045 . hal-01536401

\section{HAL Id: hal-01536401 \\ https://hal.science/hal-01536401}

Submitted on 11 Jun 2017

HAL is a multi-disciplinary open access archive for the deposit and dissemination of scientific research documents, whether they are published or not. The documents may come from teaching and research institutions in France or abroad, or from public or private research centers.
L'archive ouverte pluridisciplinaire HAL, est destinée au dépôt et à la diffusion de documents scientifiques de niveau recherche, publiés ou non, émanant des établissements d'enseignement et de recherche français ou étrangers, des laboratoires publics ou privés. 


\section{Le réseau portuaire du califat fatimide en Méditerranée (969-1171): une difficile mise en œuvre}

David Bramoullé

Université Paris 1 Panthéon-Sorbonne

L'installation des Fatimides dans le bassin oriental de la Méditerranée à partir de 969 leur permit de s'emparer de l'un des plus anciens et puissants ensembles portuaires de la Méditerranée. L'organisation de cet ensemble, dont Alexandrie, Acre, Tyr, Sayda et Tripoli constituaient quelques uns des nœuds, en un réseau portuaire cohérent au service des Fatimides, constitua un enjeu majeur pour cette dynastie au passé maritime confirmé à son arrivée en Égypte.

Dans la stratégie fatimide, l'Égypte et la Syrie ne devaient constituer que des étapes sur la route de l'Iraq, ultime objectif d'une dynastie qui considérait les Abbassides comme des usurpateurs. Mais, en proie à de multiples difficultés dans la province du Bilād al-Šām (Syrie-Palestine), dont l'intérieur ne fut jamais maîtrisé, et en Égypte même où une guerre civile (1062-1073) manqua de les renverser, les Fatimides revirent leurs prétentions à la baisse et se contentèrent de maintenir autant que possible leur pouvoir sur la bande littorale du Bilād al-šām et sur l'Égypte ${ }^{1}$. Le changement d'objectif était clair, il ne s'agissait plus de conquérir des zones lointaines mais de tenter de se maintenir au pouvoir au Caire en exploitant au mieux les potentialités offertes par les zones côtières, sources de rentrées fiscales importantes. La stratégie devait donc s'adapter en conséquence. La dynastie est par ailleurs connue pour avoir rendu à l'Égypte son rôle de plaque tournante du commerce méditerranéen et permis le développement du commerce maritime sur les divers littoraux sous son contrôle, notamment en développant le commerce des produits d'Asie arrivant par l'océan Indien et la mer Rouge. Ainsi, les cités portuaires qui pouvaient apparaître au départ comme les simples relais d'une conquête finale forcément terrestre, devinrent peu à peu autant d'éléments concourant à la survie des Fatimides, mais leur rôle militaire au sein du réseau s'en trouva alors quelque peu modifié. Le contrôle des ports du Levant et d'Égypte s'avéra un exercice difficile tant

1. Sur la présence fatimide dans le Bilād al-Šām : T. Bianquis, Damas et la Syrie sous la domination fatimide, 359-468/969-1076, 2 vol., Damas, 1984, 1989. 
du fait des mouvements de révolte, que de la présence des Byzantins à quelques encablures des littoraux sous domination fatimide ${ }^{2}$. L'établissement des califes dans leur nouvelle capitale du Caire, près de Fustat, qui devint la principale base navale de la dynastie, donnait à la capitale égyptienne un rôle majeur au sein d'un réseau portuaire en plein remodelage par rapport à la période précédente. La cité nilotique, siège d'un califat shiite qui faisait du calife le fondement de toute autorité, devint donc le centre d'impulsion unique de toutes les décisions concernant la mer, la marine et donc le réseau portuaire. Cependant, la nature des relations qui unissaient les ports entre eux et avec la capitale ne fut jamais univoque et se modifia en fonction du contexte politique qui, entre 969 et 1171, évolua considérablement.

Le réseau portuaire fatimide, qui doit se définir comme un ensemble de ports reliés et organisés entre eux par le pouvoir, n'existe en effet pas en tant que tel. Il n'eut de réalité que celle que les Fatimides voulurent ou purent lui donner. Si les premières années de la dynastie laissèrent l'impression d'une volonté califale affirmée de créer et d'organiser un réseau portuaire, la tournure que prit peu à peu le califat parait avoir quelque peu érodé les bonnes intentions initiales. Aussi le réseau en question s'avère-til difficile à appréhender tant les vicissitudes du temps en perturbèrent le fonctionnement et en masquèrent sa lisibilité dans les textes.

Les sources à notre disposition, qui vont des descriptions géographiques des auteurs musulmans aux lettres de la Geniza du Caire en passant par des chroniques ou des œuvres issues de la chancellerie fatimide, constituent un corpus relativement étoffé dont la teneur en informations relatives aux aspects maritimes peut néanmoins apparaitre bien indigente. Elles mettent malgré tout, et d'abord, en évidence que la prise de contrôle des littoraux et l'élaboration du réseau portuaire fatimide dès les premières années participait d'une stratégie qui visait au départ des Fatimides vers l'Iraq. Quelques textes permettent également d'envisager le fonctionnement du réseau portuaire fatimide, notamment les relations des ports du réseau avec la capitale ainsi que le rôle des divers ports pour la dynastie égyptienne dans le contexte singulier de modifications des objectifs politiques fatimides ainsi que de forte contraction de la façade littorale fatimide au moment des croisades. Enfin, les textes révèlent clairement les difficultés que les Fatimides eurent à contrôler l'ensemble de leur réseau, dont certains ports purent apparaître parfois comme des éléments indépendants.

2. Maqrīzī, 'Itti'āz al-ḥūnafā' bi-Ahbōr al-A'imma al-Fāțimiyyīn al-hַulafā', vol. I, éd. Ğ. Al-šayyal, Le Caire, 1967, p. 148-153. 


\section{Aux sources du réseau portuaire fatimide}

\section{Un ensemble portuaire ancien et vaste}

Lorsque les Fatimides s'installent en Égypte en 969 puis s'emparent des côtes syro- palestiniennes dans les années suivantes, ils arrivent dans un espace qui n'est pas vierge du point de vue maritime. Les côtes qui passent sous leur domination ont, pour la seule période musulmane, une histoire maritime riche. Les Umayyades puis les Abbassides avaient contribué à mettre en place un ensemble portuaire dont le rôle n'avait pas été négligeable dans la poussée musulmane en Méditerranée orientale contre les Byzantins au viII ${ }^{\mathrm{e}}$ siècle ${ }^{3}$. On connaît le récit du géographe al-Muqaddasī se rapportant à la fortification du port d'Acre par Ibn Țūlūn sur le modèle de celui de Tyr, sur la présence d'arsenaux et sur le rôle de la ceinture de ribats qui courait d'Alexandrie à Tripoli du Liban ${ }^{4}$. AuX XI ${ }^{\mathrm{e}}$ et XII ${ }^{\mathrm{e}}$ siècles les documents de la Geniza évoquent environ quinze ports entre ce qui peut apparaître comme les deux extrémités du réseau portuaire fatimide en Méditerranée orientale. Il faudrait y ajouter les ports libyens tels Barqa ou Tripoli que le calife al-Mu'izz souhaita garder sous son contrôle direct en quittant l'Ifriqiya ${ }^{5}$. Il s'agit donc d'une vingtaine de ports qui participèrent de l'ensemble portuaire fatimide à partir de 973, date de l'installation d'al-Mu'izz au Caire (cf. carte infra p. 48)'.

Les Fatimides arrivèrent donc dans un espace riche en villes portuaires qu'il fallait néanmoins conquérir car sous protectorat abbasside. L'expansion des Fatimides vers l'Égypte se fit dans un contexte oriental marqué par la reprise des offensives byzantines victorieuses contre la Crète (961), Chypre (963), et Lattaquié ou Alexandrette (968)7. Les Ihšidides, maîtres de l'Égypte et des littoraux syriens pour le compte des Abbassides, n'avaient pu s'opposer aux Byzantins. Leur incurie face aux attaques byzantines, le prestige des Fatimides dans la lutte contre ces mêmes Byzantins en Sicile et la promesse de relancer le jihad faite aux habitants de

3. A. El'Ad, « The Coastal Cities of Palestine during Early Middle Ages », The Jerusalem Cathedra 2, 1982, p. 146-167.

4. Al-Muqaddasī, Ahsan al-taqāsìm fì ma'rifat al-aqalīm, éd. M. J. De Goeje, Leyde, 1906, p. 162-163, trad. A. Miquel, La meilleure répartition pour la connaissance des provinces, Damas, 1963, p. 181-182. Sur le rôle des ribats voir Ch. Picard, A. Borrut, « Râbata, Ribât, Râbita : une institution à reconsidérer ", Chrétiens et musulmans en Méditerranée médiévale (VIIIXII siècle). Échanges et contacts, éd. N. Prouteau, Ph. Sénac, Poitiers, 2003 (Civilisation Médiévale XV), p. 34-65.

5. Maqrīzī, 'Itti' āz, op. cit., I, p. 144.

6. S. D. Goitein, A Mediterranean Society, I, Berkeley, 1967, p. 212.

7. Ibn Hawqal, Kitāb Șūrat al-arḍ, éd. G. H. Kramers, Viae et regna. Descriptio ditionis moslemicae, Leyde, 1938-1939, p. 182, trad. G. H. Kramers et G. Wiet, Configuration de la Terre, 2 vol., Paris-Beyrouth, 1964, p. 180. 


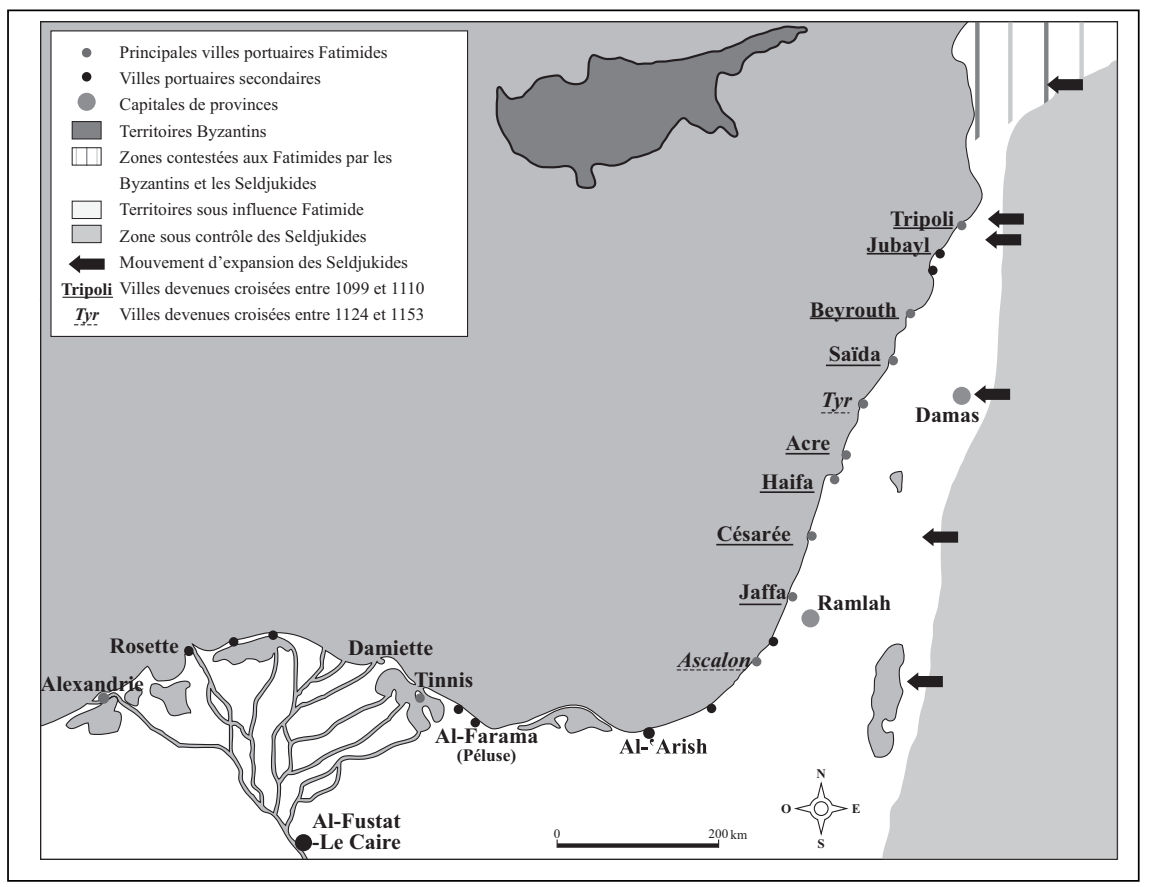

La répartition des villes portuaires fatimides en Méditerranée orientale Carte D. Bramoullé

l'Égypte par le général fatimide chargé de la conquête, Ğawhar, expliquent que les troupes maghrébines prirent le contrôle des ports égyptiens assez facilement ${ }^{8}$. Dès 970 , Ğawhar envoya des troupes à l'attaque de la province syrienne. Damas passa sous domination fatimide cette même année et les sources indiquent qu'en 971 le littoral syrien fut occupé jusqu'à Tripoli sans préciser les circonstances de la conquête fatimide. Ce silence est certainement dû à l'absence de véritable combat livré par les populations locales qui avaient compris que seuls les Fatimides étaient susceptibles de les protéger de l'ennemi byzantin.

La distance qui séparait les deux extrémités cet ensemble portuaire, près de 2800 kilomètres de littoraux, la nature des côtes et les conditions climatiques qui régnaient dans les différents ports contribuaient largement à les rendre plus ou moins praticables et donc utiles pour la dynastie. D'une manière générale, toute la côte des Syrtes était considérée comme dangereuse et le port de Tripoli de Libye était décrit comme difficile d'accès par les géographes du fait de son exposition aux vents du

8. T. Bianquis, "La prise de pouvoir par les Fatimides en Égypte », Annales Islamologiques 11, 1972, p. 50-108. Y. Lev, « The Fatimids Conquests of Egypt, Military, Political and Social Aspects », Israel Oriental Studies 9, 1979, p. 315-328. 
large 9 . Sur le littoral oriental, si les ports de Jaffa, Césarée, Tyr ou Tripoli étaient, de par leur site même, protégés des coups de vents du sud, un port comme Acre, pourtant bien fortifié, était beaucoup plus dangereux du fait de son exposition au sud ${ }^{10}$. De même, une ville littorale comme Ascalon, bien que fortifiée, ne présentait qu'un intérêt maritime limitée ${ }^{11}$. Elle ne possédait en effet aucune source d'eau douce pour les navires et son port n'était en fait qu'un simple mouillage exposé tant aux mauvaises conditions météorologiques qu'aux ennemis ${ }^{12}$. La ville contribua néanmoins comme nombre d'autres sur le littoral à entretenir la présence fatimide et contribua à la puissance portuaire et maritime de la dynastie jusqu'à sa chute aux mains des croisés en 1153.

\section{Une puissance portuaire notable}

La menace permanente que faisaient peser au $x^{e}$ siècle les Byzantins sur les divers ports évoqués, notamment ceux de la côte du Bilād al-šām, contribua à faire de la plupart des villes littorales de véritables forteresses (husūnn) maritimes. C'est du reste en ces termes que les géographes arabes qualifient les villes côtières, associant quasiment toujours l'expression de ville maritime (madīnat 'alā al-bahr) et le vocable de «fortifiée » (hașina). Les hommes qui parcourent alors ces parages livrent presque inlassablement la même description des murailles protectrices contre l'envahisseur chrétien. Sur le littoral du Šām, l'aspect défensif du port et plus largement de la ville dans laquelle il s'insère attire l'attention du visiteur qui arrive par la mer ou par la terre. Sous le califat d'al-'Azīz (975996), le géographe al-Muqaddasī rédigea une description de la côte syro-palestinienne particulièrement représentative des préoccupations de la fin du $x^{e}$ siècle : "Sayda et Beyrouth sont deux chefs-lieux côtiers fortifiés. Tripoli aussi mais elle est plus importante. » Plus au sud, Tyr « est un chef-lieu fortifié sur la mer, je dirais même en mer car on y entre par une porte unique sur un pont unique et la mer l'entoure $»^{13}$. Ibn Hawqal indique lui aussi que « Tyr est une des plus solides places fortes au bord

9. Ibn Hawqal, Șūrat al-ard, op. cit., éd. p. 69-70 ; tr. p. 65-66.

10. Nāṣir-1 Husraw, Sefer Nameh, éd. et tr. fr. Ch. Schefer, Paris, 1881, p. 49. Sur ces problèmes voir R. Gertwagen, "The Crusader Port of Acre : Layout and Problems of Maintenance », Autour de la première croisade. Actes du Colloque de la Society for the Study of the Crusades and Latin East, éd. M. Balard, Paris, 1996, p. 553-581; A. El'Ad, « Harbours and Port Facilities along the Sea Lanes to the Holy Land », Logistics and Warfare in the Ages of the Crusades, éd. J. Pryor, Aldershot, 2006, p. 95-118.

11. M. Sharon, «A New Fatimid Inscription from Ascalon », 'Atiqot 26, 1995, p. 61-86.

12. Muqaddasī, Aqālìm, op. cit., éd. p. 174 ; tr. p. 203.

13. Muqaddasī, Aqālìm, op. cit., éd. p. 160, p. 162-163 ; tr. fr. p. 176, p. 182. 
de la mer, florissante et ayant un sol fertile. On dit que c'est le lieu le plus ancien de la côte $»^{14}$. Au XI ${ }^{\mathrm{e}}$ siècle, le voyageur Nāsirir-ī Husraw, de passage sur la côte du Šām vers 1047 témoigne de la similarité des ports de cette côte :

La plupart des villes de la côte de Syrie ont un port (mina'). On donne ce nom à une darse construite pour la sécurité des navires. Elle ressemble à une écurie dont la muraille du fond s'appuie à la ville pendant que les murs latéraux s'avancent dans la mer. À leur extrémité s'ouvre une entrée de 50 guez (environ $60 \mathrm{~m}$.) et une chaîne est tendue d'un des murs à l'autre. Lorsqu'on veut faire entrer un navire dans le port (mina') on baisse la chaîne jusqu'à ce qu'elle descende sous l'eau puis on le fait passer au dessus d'elle et on la tend de nouveau afin qu'aucun ennemi ne puisse rien tenter contre les vaisseaux ${ }^{15}$.

Du côté libyen, al-Muqaddasī et Ibn Hawqal évoquent Tripoli en des termes identiques, à savoir une grande ville maritime entourée d'une muraille de pierres ${ }^{16}$. Entre les deux, les ports égyptiens occupent une place presque à part au moins chez les géographes et voyageurs des $\mathrm{x}^{\mathrm{e}}$ $\mathrm{XII}^{\mathrm{e}}$ siècles. Contrairement à leurs habitudes, les géographes ou voyageurs de cette époque ne semblent pas véritablement voir les murailles qui entouraient des villes d'Alexandrie, Damiette ou Tinnīs. Si al-Muqaddasī mentionne les «forteresses imprenables» d'Alexandrie ou de Damiette, il le fait presque en passant et s'attarde davantage sur les vestiges antiques de ces villes ou la valeur marchande de leurs productions respectives ${ }^{17}$. Ibn Hawqal, qui écrit sensiblement à la même époque qu'al-Muqaddasī, pas plus que le voyageur Nāșir-î Husraw au milieu du XI ${ }^{e}$ siècle, n'évoquent les murailles d'Alexandrie, de Damiette ou de Tinnīs qui, selon l'historien chrétien Ibn al-Muqaffā', auraient pu être détruites par les Fatimides dès les années 970 et reconstruites ultérieurement ${ }^{18}$. Tout se passe presque comme si le danger byzantin, si pressant sur les ports du Šām, n'était plus que théorique sur les côtes d'Égypte et comme si le commerce constituait

\footnotetext{
14. Ibn Ḥawqal, Șūrat al-ard, op. cit., éd. p. 174 ; tr. p. 170.

15. Nāșir-ī Husraw, Sefer Nameh, op. cit., p. 42-49.

16. Muqaddasī, Aqālìm, op. cit., éd. p. 222. Ibn Ḥawqal, Șurat al-ard, op. cit., éd. p. 68 ; tr. p. 65.

17. Muqaddasī, Aqālīm, op. cit., éd. p. 197.

18. Ibn Hawqal, Șūrat al-ard, op. cit., éd. p. 150-151 ; tr. p. 148. Nāșir-ī Husraw, Sefer Nameh, op. cit., p. 110-113, 119. Ibn al-Muqaffā', Histoire des patriarches de l'Église égyptienne, éd. et trad. anglaise A. S. Atiya, vol. II, part. 2 (880-1066), Le Caire, 1943, éd. p. 131-132, tr. p. 8889 ; Ibn Bassām, Kitāb Anīs al-Ǧălis fì Ahbār Tinnīs, éd. Ğ. D. al-Šayyāl, Mağallat al-Mağmac al-‘lmī al-'Irāqī 14, 1967, p. 151-189.
} 
la seule activité des ports égyptiens. L'évocation de garnisons par ces mêmes géographes dans les villes en question témoigne pourtant bien de l'existence d'un danger. En fait, plus que les Byzantins qui ne menacèrent que rarement la côte égyptienne, sans doute du fait de la distance qui séparait ces côtes des bases avancées byzantines de Chypre, les garnisons servaient le plus souvent à assurer le maintien de l'ordre à l'intérieur de la ville ${ }^{19}$.

Ainsi l'image qui se dégage est celle d'un ensemble portuaire constitué de ports généralement bien protégés, puissants et capables d'abriter des flottes susceptibles de se porter sur les rivages ennemis. Les dimensions du littoral qui passa sous contrôle fatimide et le nombre de ports qui devaient désormais obéir aux mêmes maîtres nécessitaient une réorganisation administrative susceptible, pour être efficace, de prendre en compte le fait que tous les ports n'étaient pas soumis au même degré d'exposition face à l'ennemi.

\section{La naissance du réseau portuaire}

Une fois maitres de l'Égypte et de la Syrie, les Fatimides procédèrent à une réorganisation administrative de ces provinces. Le vizir Ibn Killīs (m. 991), premier vizir fatimide en Égypte et réformateur de l'administration fatimide, est peut-être à l'origine de ce changement qui affecta l'administration des ports fatimides ${ }^{20}$. Il faut alors considérer cette réorganisation comme l'acte véritablement fondateur du réseau portuaire fatimide. Jusqu'à l'arrivée des Fatimides, les ports du šām se trouvaient dans les attributions traditionnelles des gouverneurs de Damas, de Tibériade ou de Ramla. Concrètement, les gouverneurs des villes côtières recevaient leurs ordres des gouverneurs de ces villes. L'historien Ibn Šaddād (m. 1235) signale néanmoins qu'avec les nouveaux maîtres les choses changèrent et que les ports du Šām passèrent sous la tutelle directe du calife fatimide via des gouverneurs locaux directement nommés par le calife et responsable devant lui seul ${ }^{21}$. Administrativement et géographiquement, les nouveaux ports fatimides en Méditerranée se trouvaient répartis entre deux provinces : l'Égypte d'une part et le Bilād al-šām d'autre part. En Égypte, à la fin du $\mathrm{x}^{\mathrm{e}}$ siècle la zone du delta du Nil se partageait en trois, voire quatre districts

19. Jean Skylitzes, Empereurs de Constantinople, éd. B. Flusin, J.-Cl. Cheynet, Paris, 2003 (Réalités byzantines 8), p. 322.

20. Ibn Hुallikān, Kitāb Waffayāt al-A‘yān, éd. I. 'Abbas, Beyrouth, 1968-1971, VII, p. 27-35. Y. Lev, "The Fatimid Vizier Ya'qūb ibn Killīs and the Beginning of the Fatimid Administration in Egypt », Der Islam 58, 1981, p. 237-249.

21. Ibn Šaddād, Al-A lāq al-Hatîra fì dịkr Umarāa al-Šām wa-l-Ğazīra, éd. S. Dahān, Damas, 1963 , p. $93,96,98,102$. 
(küra), dans lesquels les villes littorales restaient sous la dépendance des capitales de districts qui se trouvaient le plus souvent à l'intérieur du delta, à l'exception d'Alexandrie ou d'al-Faramā $\bar{a}^{22}$. Il semble que cette situation se soit perpétuée jusqu'au califat d'al-Mustanșir (1036-1094) où une réorganisation administrative fit en sorte que les ports d'Alexandrie, Nastaraw, Damiette, Tinnīs ou encore al-Faramā se répartissent dans pas moins de huit districts côtiers, dont ils étaient généralement la capitale ${ }^{23}$. La province du Šām était quant à elle partagée en six districts dont trois avaient accès au littoral : celui de Damas dont dépendaient Tripoli et les autres ports jusqu'à Sayda ; le district du Jourdain, avec Tibériade pour capitale et Tyr et Acre comme ports ; enfin, le district de Palestine, dirigé depuis Ramla et auquel appartenaient les cités côtières de Césarée, Jaffa, Ascalon jusqu'au littoral près de Gaza ${ }^{24}$. Il faut ajouter que dans les premières années du califat fatimide au moins, Barqa et Tripoli commandaient deux districts dont les gouverneurs étaient nommés par le calife du Caire. Cette transformation contribua largement à l'élaboration du réseau portuaire fatimide en mettant sous la même autorité, celle du calife ou du vizir, un ensemble de ports supposés répondre aux ordres du Caire.

Il convient donc de tenter de comprendre le rôle et le fonctionnement de ce réseau portuaire à l'aune de la politique fatimide et des transformations politiques de l'espace géographique considéré ici.

\section{Rôle et fonctionnement du réseau portuaire fatimide}

Les deux siècles de présence des Fatimides sur les côtes orientales de la Méditerranée se caractérisent par un renversement net des objectifs politiques dynastiques et un bouleversement complet du rapport de force méditerranéen avec l'arrivée des croisés. Dans ce contexte le fonctionnement du réseau portuaire et son rôle au sein de la dynastie s'en sont trouvés transformés.

22. Muqaddasī, Aqālīm, op. cit., éd. p. 193-194.

23. La liste des provinces pour la période du califat d'al-Mustanșir (1035-1094), sous lequel une nouvelle réforme administrative fut décidée, est notamment fournie par Abū Sāliḥ. Sur le littoral méditerranéen se trouvaient, d'ouest en est, Alexandrie et ses dépendances, Rosette et ses dépendances, puis les provinces dites al-Nastarāwiya, al-Ġarbiyya, Damiette et al-Abwānīya, et enfin al-Faramā. The churches and monasteries of Egypt, éd. B. T. A. Evetts, Oxford, 1895, fol. 7a. Une liste évoquant sensiblement les mêmes provinces est fournie par Ibn Mammatī, Kitāb al-qawānīn wa-l-dawāwīn, éd. A. S. Atiya, Le Caire, 1943, p. 95. Barqa et Tripoli ne sont plus à cette époque sous le contrôle véritable des Fatimides. Voir aussi A. R. Guest, " The Delta in the Middle Age », Journal of the Royal Asiatic Society, 1912, p. 941-980.

24. Muqaddasī, Aqālìm, op. cit., éd. p. 154 ; tr. fr. p. 159. 


\section{Une volonté de centralisation forte}

Il semble que les premiers califes fatimides, notamment al-Mu'izz (m. 975) et al-'Azīz, aient tenté de mettre en place un réseau portuaire très centralisé. Il s'agissait de perpétuer, mais dans un contexte géographique très différent, la politique de contrôle direct des affaires maritimes que le calife avait établi en Ifrīqiya ${ }^{25}$. Assez vite, des gouverneurs furent nommés dans les ports égyptiens pour administrer selon les volontés du calife. Les noms des exécutants, lorsqu'ils apparaissent, montrent l'appartenance de ces derniers au cercle des proches de l'imam fatimide. Cette proximité est notable à Alexandrie où, durant toute la période fatimide, seuls les familiers, les affranchis ou les plus capables des militaires issus de la garde rapprochée du calife ou du vizir furent nommés. Ainsi, Nāṣir al-Dawla Aftakin, affranchi du vizir Badr al-Ğamālī (m. 1095), exerça la charge dans les années 1080, ou bien Ibn Sallār entre 1137 et 1149, date de son accès au vizirat. Pour les autres villes portuaires égyptiennes, moins prestigieuses, les renseignements sur leurs gouverneurs sont très succincts. Les noms de certains gouverneurs comme Maš‘ala, nommé gouverneur de Tinnīs par al-Mu'izz, ou encore Sadīd al-Mulk Tu'bān ibn Muḥammad ibn Tư'bān al-Kutāmī, successivement gouverneur de Damiette puis de Tinnīs avant d'être envoyé à Alep à l'époque al-'Azīz et d'al-Hākim (994-1021), témoignent de leur appartenance à la tribu berbère des Kutāma qui composait l'essentiel de l'armée des Fatimides lors de leur installation en Égypte $^{26}$. Pour le seul règne d'al-Ḥâkim, l'historien al-Maqrīzī cite une série de gouverneurs qui confirme cette pratique. Ainsi, il mentionne les nominations de Yānis al-Hुādim puis Sandal al-Aswad à Barqa, de Fahal ibn Ismā'îl al-Kutāmī à Tyr, de Maysūr al-Hुādim à Tripoli, et de Yamna al-Hुādim à la tête de Gaza et d'Ascalon ${ }^{27}$. Le passage sous le contrôle direct du calife des ports du Šăm s'accompagna, comme en Égypte, de nominations de gouverneurs issus du sérail. Tant les Berbères Kutāma que les Slaves avaient fourni à la dynastie les plus grands généraux et administrateurs dès la période maghrébine de la dynastie (909-969). Il

25. On a un aperçu de cette centralisation des affaires navales grâce au texte narrant la vie du chambellan fatimide Ğawḍar en Ifriqiya : Al-Ğawḍarī, Sīrat Ustād Ğawdar, éd. K. Ḥusayn, M. 'Abd al-Hādī Ša'īra, Le Caire, 1954, p. 85-87, 98, 102-103, 119, 137 ; tr. fr. M. Canard, Vie de l'ustadh Ğaudhar, Alger, 1958, p. 125-127, 146, 154-156, 180, 209. Sur le contexte géographie et ses incidences sur la politique navale fatimide voir notamment: Y. Lev, « The Fatimid Navy, Byzantium, and the Mediterranean Sea, 996-1036 », Byzantion 54, 1984, p. 220-252.

26. Ibn al-Muqaffā', Histoire des patriarches, op. cit., éd. p. 132, tr. p. 89. Yahyā Ibn Sa'̄̄d Al-Anțākī, Ta'rīh al-Anțākī, éd. U. A. Tadmurī, Beyrouth, 1990, p. 492-495.

27. Maqrīzī', 'Itti'āă, op. cit., I, p. 300. 
semble que les premiers califes poursuivirent cette politique ${ }^{28}$. Tenir fermement les ports apparaissait alors comme essentiel pour continuer la progression sur la route de l'Iraq abbasside. L'intérêt qu'un calife comme al-Mu'izz, dont il faut rappeler qu'il avait été sinon le créateur de la marine fatimide, du moins celui qui avait le mieux compris son importance pour la dynastie, portait à la conquête et à la maîtrise des ports syropalestiniens, transparait dans le mouvement de troupes qu'il ordonna afin de porter secours à Beyrouth, alors sous la menace byzantine, plutôt que de poursuivre l'attaque contre Damas ${ }^{29}$.

Si les représentants des Fatimides furent souvent choisis dans la garde rapprochée du calife fatimide, il n'en demeure pas moins qu'il ne leur fut octroyé que peu de marge de manœuvre en ce qui concerne les décisions qu'ils pouvaient être amenés à prendre une fois à la tête d'une cité côtière. La volonté califale primait et la moindre action des gouverneurs locaux, dès lors qu'elle engageait la troupe, devait recevoir l'aval du calife. Ainsi, en 998, sous le calife al-Hākim (996-1021), la ville de Tyr se souleva contre la présence maghrébine. Les gouverneurs de cités côtières proches de Tyr ne prirent aucune initiative et n'agirent pas avant que le général Ğayš Ibn Samșāma, chargé par le calife de reprendre la ville, n'ordonne au cadi de Tripoli et au gouverneur de Sayda d'expédier des navires ${ }^{30}$. Dans cette logique, vers 1009-1010, le cadi de Tripoli 'Alī Ibn Ḥaydara fut décapité après avoir confié la gestion de la ville d'Alep, capitale stratégique de la Syrie du nord, à un certain Manșūr b. Lu'lu', lequel avait déjà été reconnu par le calife al-Hākim comme maitre de la ville au nom des Fatimides ${ }^{31}$. Il était notamment reproché au cadi de ne pas avoir envoyé ses pigeons voyageurs pour recueillir l'avis final du calife. Outre les pigeons, les textes signalent également l'existence d'un système de courrier maritime qui faisait le trajet très fréquemment entre les ports de Syrie et l'Égypte. Les navires devaient être rapides, car en plus du rapport des événements survenus dans le Bilād al-šām, le texte précise également que l'embarcation, d'ailleurs qualifiée de pigeon (hamāma), transportait la neige glacée utilisée pour faire les sorbets dont raffolait le calife al-Hākim ${ }^{32}$.

28. F. Dachraoui, Le califat fatimide au Maghreb : 296-362/909-973, Tunis, 1970, p. 355-357. H. Halm, The Empire of the Mahdi, The Rise of the Fatimids, Leyde, 1996, p. 338-342.

29. Halm, The Empire of the Mahdi, op. cit., p. 392-395. Lev, « The Fatimid Navy », art. cit., p. 243.

30. Yahyā Ibn Sa‘̄id, Ta’rīh al-Anțākī, op. cit., p. 241. Ibn al-Qalānisī, Dayl Ta'rīhn Dimašq, éd. H. F. Amedroz, Leyde, 1908, p. 50.

31. Yahyā Ibn Sa'īd, Ta'rīh al-Anțākī, op. cit., p. 317, note 2. Ibn al-'Adīm, Zubdat al-halab min Ta'rīh Halab, I, éd. S. Dahhān, Damas, 1951, p. 199-200.

32. Yahyā Ibn Sa'īd, Ta'rīh al-Anțākī, op. cit., p. 290. Musabbiḥ̄ì Tome quarantième de la Chronique d'Égypte, éd. A. Fu'ad Sayyid, T. Bianquis, Le Caire, 1978, p. 68. 
La volonté affichée de contrôler fermement les différents ports du réseau à partir du Caire masque cependant des disparités. L'ampleur du réseau portuaire à maîtriser créait, à elle seule, les facteurs de la division du réseau en plusieurs ensembles.

\section{Un réseau portuaire divisé et hiérarchisé}

Le réseau portuaire fatimide était loin d'être homogène. La période fatimide a vu, sinon l'apparition, du moins l'accentuation d'une division de ce réseau en deux ensembles distincts, mais aussi la création d'une hiérarchie tant entre ces deux ensembles qu'à l'intérieur. La première rupture à l'intérieur du réseau portuaire était d'ordre géographique. Il n'y avait pas de port fatimide véritable entre Tinnīs et Ascalon, première ville portuaire importante de Palestine en dépit de la médiocrité de son mouillage située à environ 260 kilomètres par la côte et 216 kilomètres en ligne droite de Tinnīs ${ }^{33}$. La division géographique était renforcée par une autre, d'ordre administratif. Surtout, la division principale reposait avant tout sur le rôle que jouaient ces deux ensembles pour la dynastie et peutêtre aussi sur la manière dont les ports furent administrés.

Le privilège de l'éloignement des zones de conflit constituait l'apanage de la partie égyptienne du réseau portuaire. Plus difficiles d'accès pour les flottes byzantines, les villes côtières égyptiennes furent donc moins souvent attaquées que les ports syro-palestiniens, notamment dans les premières années de la présence fatimide, période où les relations entre les deux puissances furent tendues. Cela put se manifester concrètement par un moindre soin porté au système défensif de ces villes. Ainsi, Tinnīs n'avait ni gouverneur fatimide ni troupe lorsqu'une révolte éclata en 975. Si des troupes furent envoyées et reprirent difficilement le contrôle de la ville, l'auteur qui raconte ces événements indique que les murs de la cité furent abattus et restèrent peut-être longtemps en l'état. L'historien égyptien al-Maqrīzī signale en effet que Damiette et Tinnīs virent leurs enceintes reconstruites ou restaurées « après la chute des villes frontières (tugiūr) de Syrie aux mains des Francs $»^{34}$. Le danger moins pressant qui menaçait les villes égyptiennes pendant tout le $\mathrm{x}^{\mathrm{e}}$ et le $\mathrm{xI}^{\mathrm{e}}$ siècle eut aussi

33. Muqaddasī, Aqālìm, op. cit., éd. p. 174, tr. p. 203.

34. Maqrīzī, 'Itti'àz, op. cit., I, p. 317. L'historien chrétien Ibn al-Muqaffā' indique qu'un membre éminent de la communauté chrétienne de Tinnīs écrivit au calife al-Mu'izz pour lui demander d'envoyer un gouverneur et des troupes car de jeunes musulmans terrorisaient la population locale composée majoritairement de chrétiens. Le calife envoya des hommes qui assiégèrent la ville et, une fois à l'intérieur, tuèrent les rebelles. L'auteur finit en indiquant que le gouverneur détruisit les murs de la cité. Ibn al-Muqaffā', Histoire des patriarches, op. cit., éd. p. 131-132 ; tr. p. 88-89. 
des conséquences administratives car durant toute cette période les textes ne citent pas les villes littorales égyptiennes parmi les túgūur. Il fallut donc attendre les croisades, vraisemblablement le vizirat d'al-Ma'mūn al-Bața'ihī (1121-1128) pour que les ports égyptiens rentrent dans la catégorie des postes frontières et qu'une administration particulière, différente de l'administration dont ils dépendaient jusqu'alors, leur soit appliquée ${ }^{35}$.

En Égypte même, les choses paraissent atypiques tant les califes fatimides semblent avoir poussé loin leur volonté de centralisation. Tant d'un point de vue commercial que pour l'activité de construction navale, le port majeur pour les Fatimides n'était pas Alexandrie ou Damiette mais bien l'ensemble Fustat-Le Caire ${ }^{36}$. Le nombre d'arsenaux, leur localisation précise le long de la rive du Nil s'avèrent difficiles à déterminer et la polysémie du terme même d'arsenal (dār al-șinā $\bar{c}^{c} a$ ), qui pourrait en effet désigner tout autant une zone artisanale qu'un lieu de construction navale, rend plus malaisée encore l'interprétation des textes ${ }^{37}$. Les auteurs n'accordèrent que peu d'attention à ces lieux bruyants où l'odeur du bois se mélangeait à celle de la poix chaude. Quelques épisodes particulièrement marquants permirent néanmoins à ces sites de sortir de l'anonymat complet. Ainsi l'arsenal dit d'al-Maqs, près du Caire, pourrait avoir été le théâtre de l'incendie de la flotte attribué aux marchands Amalfitains en

35. Le vizirat d'al-Ma'mūn est connu par le récit qu'en fit son fils, Ibn al-Ma'mūn (m. 1193), qui s'appuya sur des pièces d'archives. Il s'agit ainsi du premier texte relativement contemporain des événements dans lequel un port comme Alexandrie est qualifié de tagir. Ibn al-Ma'mūn, Passages de la Chronique d'Égypte d'Ibn al-Ma'mūn, éd. A. Fu'ad Sayyid, Le Caire, 1983, p. 65. Sur l'administration relative aux postes frontières, voir Ibn al-Ṭwayr, Nuzhat al-Muqlatayn fï Ahbār al-dawlatayn, éd. A. Fu'ad Sayyid, Beyrouth, 1992, p. 92.

36. Sur la domination du port de Fustat sur Alexandrie voir notamment A. L. Udovitch, " A Tale of Two Cities : Commercial Relations between Cairo and Alexandria during the Second Half of the $11^{\text {th }}$ Century », The Medieval City, éd. H. A. Miskimin, New Haven, 1978, p. 143-162 ; Id., "Medieval Alexandria : Some Evidences from the Cairo Genizah Documents ", Alexandria and Alexandrianism, Malibu, 1996, p. 273-284 ; Id., " Alexandria in the $11^{\text {th }}$ and $12^{\text {th }}$ Centuries. Letters and Documents of the Cairo Geniza Merchants : an Interim Balance Sheet ", Alexandrie Médiévale 2, éd. Ch. Décobert, Le Caire, 2002, (Études Alexandrines 8), p. 99-112.

37. C'est en fait l'usage qui a systématiquement conduit à prendre pour traduction de dār al-șinăa le terme d'arsenal. Le sens semble en fait plus large et seul le contexte de la phrase peut permettre de savoir si le texte évoque réellement un arsenal ou simplement une zone d'artisanat. Sur ce problème voir notamment: Cl. Cahen, « Douanes et commerce dans les ports méditerranéens de l'Égypte médiévale ", Journal of the Economic and Social History of the Orient 7, 1964, p. 217-314. Ch. Picard, « Les arsenaux musulmans de la Méditerranée et de l'océan Atlantique $\left(\mathrm{VII}^{\mathrm{e}}-\mathrm{XV}^{\mathrm{e}}\right.$ siècle) », Chemins d'outre-mer. Études sur la Méditerranée médiévale offertes à Michel Balard, éd. D. Coulon, C. Otten-Froux, P. Pagès, D. Valérian, Paris, 2004, p. 693-710. 
996 (plan p. 59), mais la chose n'est pas claire ${ }^{38}$. À partir d'un certain moment du califat d'al-Ḥākim un arsenal apparut plus au sud, à Fustat, où le calife venait en grand cortège afin de participer aux cérémonies du Nilomètre $^{39}$. Le site d'al-Maqs fut peut-être abandonné mais il demeura cependant le port de stationnement des navires de plaisance califaux où, au milieu du XI ${ }^{\mathrm{e}}$ siècle, ils étaient remisés dans un bassin tels « des mulets dans une écurie ${ }^{40}$. Sans que l'on sache exactement à quelle date, les califes déplacèrent de nouveau le site de l'arsenal pour l'île de Rawda, dont les textes indiquent qu'il avait été abandonné vers 937 au profit du site de Fustat ${ }^{41}$. Il s'agissait donc d'une sorte de retour en arrière. En 1123, le vizir al-Ma'mūn al-Bața'iḥ̄, mécontent du fait que tous les navires de la flotte fussent construits sur ce seul site insulaire, modifia cette organisation en ordonnant que soient construits dans l'arsenal de Fustat (șinā'a bi-Mișr) les navires du dīwān destinés à la navigation sur le Nil (al-marākib al-nīlìyat al-dīwānīya) ainsi que les galères de combat (šawānī), alors que les bâtiments de transport (šalandiyāt) et les navires dits ğirān̄ auraient continué à être mis en chantier dans l'île (șanā'at bi-l-ğazīra). Pour ce faire, il décida d'agrandir le site de Fustat: l'étroitesse de celui-ci et l'intensité du trafic fluvial pourraient donc être les causes du transfert à Rawda en 937, en y annexant un bâtiment commercial. Il fit également construire un pavillon dans lequel le calife venait assister à la revue de la flotte ${ }^{42}$. L'administration du ou des sites utilisés pour la construction est largement aussi floue que leur localisation. Il se dégage néanmoins des textes quelques termes : chargé de la șinā'a (mutawali al-șināa $a$ ), ou « préposé à la construction des navires du diwān » (mutawal̄ 'imārat marākib al-diwān) qui mettent en évidence une liaison privilégiée des fonctionnaires impliqués dans la gestion du site ou dans la construction navale avec le calife ou le vizir ${ }^{43}$. Une lettre, ou plus exactement un brouillon d'une pétition adressée au calife al-Mustanșir, fait également allusion à un Kātib

38. Musabbiḥ̄ī, Nuṣūṣ al-ḍ̂̀’ ía min Ahbār Miṣr, éd. A. Fu'ad Sayyid, Annales Islamologiques 17, 1981, p. 15-16. Yahyā Ibn Sa'īd, Ta'rīh al-Anțākī, op.cit., p. 233-234. Cl. Cahen, « Un texte peu connu relatif au commerce oriental d'Amalfi au $\mathrm{x}^{\mathrm{e}}$ siècle ", Archivio Storico per le Province Napoletane n. s. 34, 1954, p. 3-8.

39. Ibn Muyassar, Ahbār Miṣr, éd. A. Fu'ad Sayyid, Le Caire, 1981, p. 180.

40. Nāșir-1̄ Husraw, Sefer Nameh, op. cit., p. 48.

41. Ibn Sa'īd, Al-muġrib fi ḥulā al-Maġrib, éd. Z. M. Hasan, S. I. Kāšif, S. Ḍayf, Le Caire, 1953, p. 12-13.

42. Ibn al-Ma'mūn, op.cit., p. 101-102.

43. Le calife n'était d'ailleurs pas au courant d'une telle pratique et la fit interdire par lecture d'un décret en chaire dès qu'il en eut connaissance. Musabbiḥ̄ī, Tome Quarantième, op. cit., p. 38-39, 53, 95. M. Gil, Be-malkhūt Yishmael be-tkufat ha-geonīm, vol. II, Jérusalem, 1997, p. 875-880 (lettre : TS NS J198). 
al-șina $\bar{a}^{\star} a$ (Secrétaire de la șināa $\bar{a}^{\prime} a$ ) mentionné en tant qu'intermédiaire influent dans une lutte opposant deux communautés juives ${ }^{44}$.

Certaines questions se posent évidemment quant à l'existence d'arsenaux fatimides dans les autres ports égyptiens, notamment Alexandrie et Damiette. Quelques sources évoquent effectivement le terme d'arsenal $\left(\sin ^{\dagger} \bar{a}^{\natural} a\right)$ à propos de ces ports ${ }^{45}$. Les textes, rédigés par deux membres de l'administration ayyoubide, font cependant allusion à une période dont les spécialistes ne savent pas avec certitude si elle fait référence aux Fatimides ou aux Ayyoubides ${ }^{46}$. La logique fatimide de gestion directe de tout ce qui touchait à la marine de guerre, le danger qu'ils voyaient à faire construire des navires de guerre dans des ports susceptibles d'être attaqués par des ennemis ou qui s'étaient soulevés contre les Fatimides, rendent peu probable l'existence d'arsenaux officiels dans les villes d'Alexandrie ou de Damiette, au moins jusqu'aux années 1160. Les quelques textes qui signalent l'arrivée de bois de construction navale à Alexandrie indiquent aussi que ce bois était ensuite transporté à Fustat $^{47}$. Cela n'exclut pas pour autant la présence de chantiers privés destinés à construire les navires de commerce. Il apparaît également que lorsqu'une flotte partait pour une expédition, le calife se déplaçait jusqu'à un pavillon sur le Nil et assistait à une parade navale où les navires de la flotte se livraient à divers jeux nautiques qui reproduisaient des situations de combat ${ }^{48}$. L'existence de ce type de manifestations publiques mettant en scène le pouvoir naval du califat nécessitait la présence de la majeure partie de la flotte là où elle avait été mise en chantier, c'est-à-dire près de la résidence du calife. Ainsi, à l'intérieur de l'Égypte fatimide, les ports maritimes étaient dans une situation presque de dépendance à l'égard de Fustat et du Caire où l'essentiel de la construction navale militaire paraît avoir été effectuée. Bien plus, à aucun moment les sources ne

44. Lettre TS Arabic Box 30, f. 278 + Bodl. MS Heb. b 18, f. 21. Publiée par M. Gil, Erets Yisrael be-tkufat ha-muslemit ha-rishōna (634-1099), vol. 2, Jérusalem, 1983, p. 347-355. S. Stern a également édité et traduit cette lettre : «A Petition to the Fāțimid Caliph al-Mustanșir Concerning a Conflict within the Jewish Community », Revue des Études Juives 78, 1969, p. 203-222. Stern pense notamment qu'il faut peut-être traduire șină $\bar{a}^{\prime} a$ par douane et non pas par arsenal ou chantier naval. Il confirme néanmoins que le secrétaire en question était un personnage haut placé de l'Administration fatimide.

45. Al-Maȟzumī, Kitāb al-Minhağ fī ilm ḩarāğ Miṣr, éd. Cl. Cahen, Paris, 1986, p. 10, 46. Ibn Mammatī, Kitāb al-qawānīn, op. cit., p. 95.

46. Cl. Cahen, «Douanes et commerce dans les ports méditerranéens de l'Égypte médiévale », Journal of the Economic and Social History of the Orient 7, 1964, p. 217-213.

47. Ch. Pellat, Cinq calendriers égyptiens, Le Caire, 1986, p. 60, 74, 92.

48. Al-Qalqašandī, Subḥ al-A ‘̌s̄ fì șinā'at al-inšā', éd. M. H. Šams al-Dīn, vol. III, Beyrouth, 1987, p. 596-597. 


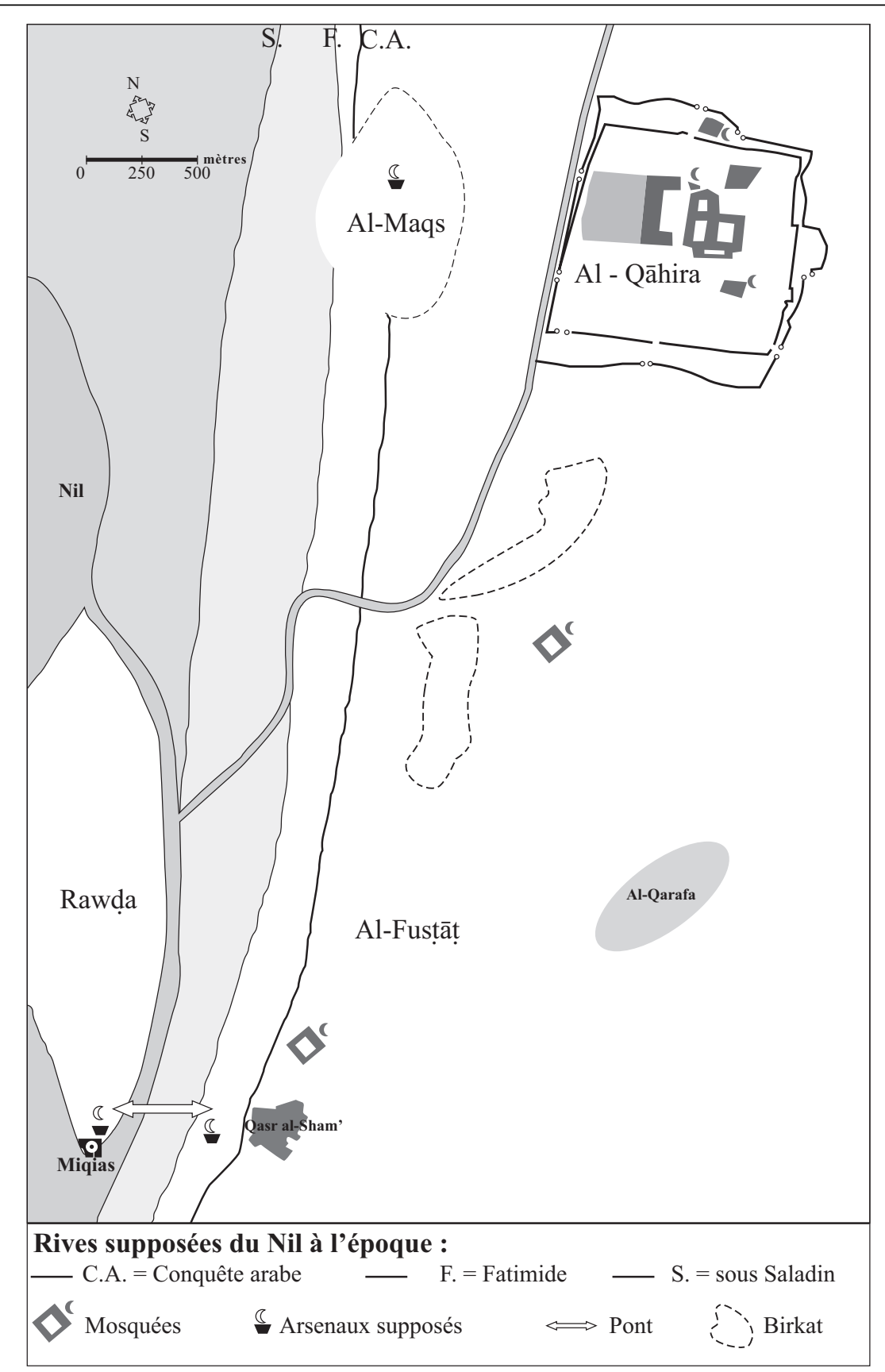

L'ensemble urbain al-Fustât-Le Caire : possibles lieux de localisation des arsenaux. 
mentionnent clairement l'existence d'un arsenal, c'est-à-dire un chantier naval procédant d'une volonté étatique, hors de l'Égypte. Nāṣir-ī Husraw s'étonne même de la présence de charpentiers de marine à Haïfa. Il devait s'agir là d'une nouveauté car dans son trajet le long de la côte syropalestinienne il n'en avait encore signalés aucun ${ }^{49}$. La place centrale donnée à l'Égypte dans la stratégie navale fatimide s'explique donc en grande partie par la concentration des organes de commandement entre les mains du calife ou du vizir ainsi que par le mode de gestion des autres cités côtières de Palestine et de Syrie. Les Fatimides paraissent avoir été très conscients de l'importance de la marine dans la formation de leur pouvoir et de l'obligation qu'il y avait à en disperser le moins possible les éléments et le commandement. Ainsi, toutes les expéditions navales pour lesquelles les textes donnent quelques détails mettent en évidence une chaîne de commandement très courte et extrêmement centralisée. La période des croisades, avec les menaces que les flottes chrétiennes firent peser sur les ports égyptiens, renforça encore un peu plus la concentration de la construction navale et peut-être même de la localisation des flottes de guerre à Fustat. Alexandrie, Damiette ou Tinnīs apparaissent en ces années fatimides bien plus comme des villes de commerce que comme des villes de garnison.

Du côté du littoral syro-palestinien, les villes portuaires syriennes remplirent dans un premier temps un rôle militaire et cela pour plusieurs raisons. La première était avant tout lié à la proximité géographique avec les territoires byzantins. Au $x^{\mathrm{e}}$ siècle, les cités portuaires du Šām se trouvaient particulièrement menacées par les Byzantins, alors en pleine expansion en Syrie du nord. Les chroniqueurs arabes mentionnent les raids chrétiens menés contre les ports dans les toutes premières années de l'installation des Fatimides dans la région ${ }^{50}$. Aussi les ports de Syrie et de Palestine rentraient-ils dans la catégorie particulière des postes frontières de l'Islam, des tugiür (sing. tágr), susceptibles de subir les assauts des flottes chrétiennes et lieux privilégiés de l'accomplissement du jihad pour les plus pieux des musulmans ${ }^{51}$. Tripoli de Syrie était le port où les habitants de Damas venaient accomplir leur « service de ribat » durant le temps de la saison de la navigation et Tortose est mentionné comme «un poste frontière

49. Nāṣir-1̄ Husraw, Sefer Nameh, op. cit., p. 60.

50. Sur cet aspect, voir entre autres sources Yahyā Ibn Sa'īd al-Anțākī, Ta'rīh al-Anțākī, op. cit., p. 229-230, 241, 245-246. Nuwayrī, Nihāyat al-'Arab fï funūn al-ā'dab, XXVIII, Le Caire, 1992, p. 150-151, 158-159. Ibn al-Dawādārī, Kanz al-Durar wa ğāmi al-ġurar, VI, éd. S. al-Munağğid, Le Caire, 1961, p. 170-171, 232.

51. Sur le terme de tağr voir notamment « Thughūr », Encyclopédie de l'islam², X, p. 446b (J. D. Latham, C. E. Bosworth). 
(tağr) pour les habitants de Homs » avant que la ville ne passe aux mains des Byzantins ${ }^{52}$. Les Fatimides devaient faire le nécessaire pour remplir leur promesse faite aux habitants de l'Égypte, aux réfugiés de Tarse, de Cilicie, installés en Syrie ou en Palestine, de relancer le jihad. Il y avait donc là un aspect surtout idéologique pour une dynastie shiite qui exerçait son pouvoir sur des sujets principalement sunnites. Il fallait leur donner des gages de bonne volonté et les rassurer sur le fait que les nouveaux maîtres, en dépit de leur shiisme, allait mener une action que les Ihšidides, des sunnites, n'avaient pas accomplie. Cette politique visait sans aucun doute à s'assurer le calme des populations de ces ports qui étaient surtout destinés à accueillir les troupes nécessaires à la poursuite de l'avancée vers l'Iraq, au moins dans les premières décennies fatimides. Dans cette situation, tout ce qui concernait la défense portuaire devait revêtir un caractère hautement stratégique. Séparer des attributions des gouverneurs de district la gestion des villes côtières pour la placer sous la coupe directe du calife ou de son vizir, créer une administration différente du dīwān al-Šām, bureau traditionnellement chargé de la gestion de cette province, pour ces postesfrontières, c'était d'abord envoyer un message aux populations locales qui attendaient que les engagements soient tenus. C'était aussi raccourcir la chaîne de commandement entre les postes-frontières et le Caire. Cela consistait enfin à affaiblir les gouverneurs de Damas, Ramla ou Tibériade, chose que les Fatimides ne négligèrent jamais car ils redoutaient de voir un gouverneur provincial trop puissant.

Les ports syro-palestiniens constituaient autant de bases avancées ou, selon le contexte, de bases arrières permettant la future conquête. Les villes littorales en question se muèrent pourtant parfois en derniers bastions de la présence fatimide en Syrie-Palestine, faisant peu à peu prendre conscience aux maîtres de l'Égypte de la fragilité de leur mainmise sur ces provinces. En effet, dès les années 970 , outre les attaques byzantines, les Fatimides furent confrontés à la progression des Qarmates. Ces derniers menacèrent très sérieusement la présence fatimide dans la province du Šām en s'emparant peu à peu de l'intérieur. Seules les villes littorales restèrent alors sous autorité fatimide ${ }^{53}$. La décennie 1020-1030 fut également très agitée pour la présence fatimide dans le Šām. Les révoltes bédouines, les problèmes à Alep et Damas, entraînèrent pendant quelques temps une perte de contrôle de l'intérieur de la Palestine et de

52. Ibn Hawqal, Șūrat al-ard, op. cit., éd. p. 175, 177-178 ; tr. p. 172, 173.

53. Maqrīzī, 'Itti' $\bar{a} z$, op. cit., I, p. 168, 178, 194, 200, 204, 247. Ta'rīh Ahbār al-Qarāmița, éd. S. Zakkār, Beyrouth, 1981, p. 58-59, 64-65, 67, 106. Bianquis, Damas et la Syrie, op. cit., I, p. 5689. H. Halm, Die Kalifen von Kairo, Munich, 2003, p. 92-99. 
la Syrie ${ }^{54}$. Les ports furent assiégés et les troupes égyptiennes ne reprirent le contrôle des territoires perdus que difficilement et souvent à partir des ports dont les rebelles n'avaient jamais pu s'emparer. Conserver ces ports constituait d'autre part un moyen de s'assurer des rentrées fiscales importantes. Ces ports du Šām jouèrent en effet un rôle économique non négligeable pour la dynastie. La description que livre Nāṣir-ī Husraw de tous les ports du réseau syro-palestinien, laisse un sentiment de prospérité. Les souks étaient bien fournis, les marchands étrangers nombreux. Une prospérité qui contribuait également à assurer la défense de ports comme Tripoli car, selon les textes, les taxes servaient à entretenir les soldats qui participaient à la défense de la ville contre les chrétiens ${ }^{55}$. La prospérité des ports du Šām au milieu du XI ${ }^{\mathrm{e}}$ siècle s'explique enfin largement par la signature de plusieurs trêves entre les Fatimides et les Byzantins ${ }^{56}$.

À l'intérieur de cet ensemble constitué par les ports du Šām, quelques textes pourraient indiquer qu'il existait une hiérarchie. Tripoli et Tyr paraissent se détacher des autres cités côtières par la qualité de leurs fortifications et de leurs mouillages. Tripoli constituait le pôle majeur de cette partie du réseau, du fait encore une fois de sa localisation. Nāṣir-ī Husraw décrit en outre le système de défense de Tripoli contre les entreprises ennemies avec son fossé, ses fortifications et ses balistes, alors qu'il passe plus rapidement sur les autres cités de la côte ${ }^{57}$. Le soin particulier que portait la dynastie à l'égard de Tripoli s'explique sans doute aussi par son rôle de port d'exportation des céréales syriennes vers l'Égypte. Il était donc essentiel pour la dynastie égyptienne de contrôler ce port particulier. L'épisode de la révolte de Tyr met en évidence que seuls quelques ports possédaient des flottilles de guerre, notamment celui de Tripoli et de Sayda. Pourquoi, en effet, demander une assistance navale aux navires de ces deux cités plutôt qu'à ceux de Beyrouth ou même d'Acre, deux ports situés bien plus près de Tyr ? Cela signifie qu'il n'y avait pas de flottes de guerre à Acre, Beyrouth ou Jubayl car leurs mouillages n'offraient sans doute pas une protection satisfaisante contre les intempéries ou étaient trop petits, comme l'indiquera Ibn Ğubayr quelques années plus tard à propos d'Acre ${ }^{58}$. À

54. M. Gil, « Milhemet shishīm ha-shanīm (969-1029 C.E.) », Shalem 3, 1981, p. 1-55 (en hébreu) ; Id., The History of Palestine, 634-1099, New York, 1997, p. 335-429.

55. Nāșir-ī Husraw, Sefer Nameh, op. cit., p. 40-41.

56. Maqrīzī, 'Itti'āz, op. cit., II, p. 172, 187, 194, 202. Yahyā Ibn Sa'īd, Ta'rīh al-Anțākì, op.cit., p. 376-377. Skylitzes, Empereurs de Constantinople, op. cit., p. 284. Bianquis, Damas et la Syrie, op. cit., I, p. 309.

57. Nāșir-1̄ Husraw, Sefer Nameh, op. cit., p. 40-41.

58. Ibn Jubayr, Relations de voyages, trad. fr. P. Charles-Dominique, Voyageurs Arabes, Paris, 1995, p. 328. 
l'inverse, les bassins fortifiés de Tyr, Sayda ou Tripoli pouvaient accueillir des flottilles en toute sécurité. Ainsi les Fatimides paraissent avoir choisi quelques ports seulement pour disposer des bâtiments de guerre.

À évoquer le rôle militaire de ces cités côtières, il faut pourtant bien constater qu'en dehors de la révolte de Tyr en 998 et de la mention d'envoi de navires depuis Tripoli et Sayda, les textes ne signalent pas clairement d'expédition navale organisée à partir des ports du littoral syrien. Les allusions à des flottes locales sont rares. Le voyageur persan Nāssir-i-i-Husraw signale bien que « le sultan possède à Tripoli des navires qui se rendent en Grèce, en Sicile, au Maghreb pour y faire le commerce », ce qui tendrait à montrer qu'il existait bien dans ce port une flotte au service des Fatimides. Mais il semble clair que la vocation première de ces navires était le commerce, et peut-être secondairement la guerre ${ }^{59}$. L'absence de réelle spécialisation ou de franche séparation entre les bâtiments de guerre et les bateaux de commerce, un navire de fret pouvait en effet être considéré comme un navire de guerre à partir du moment où des soldats embarquaient dessus, laisse supposer que ces navires furent parfois utilisés pour le combat, même si les choses ne sont jamais expliquées aussi clairement dans les sources ${ }^{60}$. Les textes mentionnant des flottes fatimides sur la côte du Šām se réfèrent le plus souvent à des flottes envoyées d'Égypte, et quasiment jamais des escadres locales permanentes.

Paradoxalement, le rôle naval des ports syro-palestiniens parait donc assez limité. Ils constituaient davantage des bases de relais pour le déplacement des navires arrivant d'Égypte que de véritables bases navales où stationnaient des escadres conséquentes. Les quelques bâtiments de guerre placés dans les ports mentionnés servaient en fait essentiellement à assurer la sécurité des routes commerciales. Il faut en effet toujours se rappeler que les Fatimides eurent un grand intérêt dans le commerce maritime. Il faut aussi se remémorer l'objectif final de la dynastie : la conquête de l'Iraq abbasside qui passait par la maîtrise de la Syrie intérieure. En aucun cas les Fatimides n'eurent pour ambition de partir à l'assaut de Chypre, de la Crète ou d'un quelque autre territoire byzantin accessible par mer. Tous leurs objectifs étaient, jusqu'au milieu du xI siècle au moins, continentaux ${ }^{61}$. Il était donc assez logique que les ports du šām ne soient

59. Nāṣir-1̄ Husraw, Sefer Nameh, op. cit., p. 42.

60. La grande majorité des vaisseaux n'étaient pas destinés à faire la guerre sur mer, les mentions de batailles navales étant extrêmement rares, mais simplement à transporter des troupes et du matériel de guerre d'un endroit à un autre.

61. L'échec de la prise de Bagdad au nom des Fatimides par le général turc al-Basāsīrī en 1059, puis le début de la guerre civile et l'arrivée au pouvoir de Badr al-Ğamālī en 1073, paraissent avoir scellé la fin des rêves expansionnistes fatimides. Sur l'échec de la prise de 
pas pourvus de flotte conséquente : cela ne faisait simplement pas partie de la stratégie et cela n'était pas utile. Les sources relatant l'épisode célèbre du transfert des troupes du général Badr al-Ğamālī de Acre à Damiette en plein hiver 1072-1073 mentionnent l'utilisation de cent navires ${ }^{62}$. Il ne peut en aucun cas être question de navires de guerre fatimides basés à Acre. Il faut comprendre ici, outre l'exagération évidente du nombre d'embarcations, qu'il s'agissait de navires de commerce affrétés pour l'occasion et peut-être mis en chantier auparavant à Haïfa, où en 1047 Nāṣir-1̄ Husraw avait remarqué le " grand nombre d'ouvriers occupés à construire des navires " qu'il disait alors destinés à " la navigation maritime $»^{63}$. Le fait que les textes narrant l'épisode indiquent qu'à peine arrivé en Égypte, Badr obtint de l'argent des marchands de Tinnīs, souligne bien que les commerçants avaient tout intérêt à aider Badr dans sa tentative pour restaurer l'ordre en Égypte et dans tous les territoires fatimides en proie depuis dix années à une guerre civile. Prêter leurs navires pouvait donc tout à fait participer de cette aide. Les croisades ne semblent pas avoir entraîné une modification fondamentale de ce système. En effet, lorsque des escadres locales sont mentionnées, il s'agit encore une fois de quelques navires seulement. Ainsi, en 1103, douze galères quittent les ports de Sayda et de Tyr pour porter secours au port $\mathrm{d}^{\prime}$ Acre $^{64}$. Les navires prennent toujours la mer depuis Tripoli, Tyr ou Sayda, comme ce fut le cas en $1109^{65}$. Cette phase critique pour la domination fatimide sur ces littoraux syro-palestiniens que constitua l'avancée des croisés ne modifia en fait que peu la donne en terme d'utilisation de la flotte et des ports par les Fatimides. Il s'agissait toujours pour eux d'éviter aussi longtemps que possible que les villes ne passent aux mains des ennemis, qu'ils soient Byzantins ou Francs. S'il est évident que le champ d'action de la flotte fatimide se trouva réduit par la perte de tous les ports entre Tripoli et l'Égypte, la manière d'utiliser les navires ne changea pas fondamentalement. Plus qu'un rôle véritablement naval, les ports du Šām constituèrent durant toute la période fatimide surtout des points de stationnement de troupes terrestres.

Bagdad voir notamment M. K. Husayn (éd.), Sìrat al-Mu'ayyad fì-l-Dīn dā't̄ al-du'āt, Le Caire, 1949, p. 135, 178-184. V. Klemm, Memoirs of a mission, The Ismaili Scholar, statesman and poet al-Mu'ayyad fi'l-Dîn al-šîrâzî, Londres, 2003, p. 85-87.

62. Ibn Muyassar, Ahbāar Miṣr, op. cit., p. 40. Maqrīzī, 'Itti'āạ, op. cit., II, p. 311.

63. Nāṣir-1̄ Husraw, Sefer Nameh, op. cit., p. 60.

64. Ibn al-Ațīr, Al-Kāmil fï-l-Ta'rīh, X, Beyrouth, 1979, p. 345.

65. Ibid., p. 476. J. Richard, « Les bases maritimes des Fatimides », Egypt and Syria in the Fatimid, Ayyubid, Mamluk Eras, I, éd. U. Vermeulen, D. De Smet, Louvain 1995 (Oriantalia Lovaniensia Analecta 73), p. 115-129. 
En matière d'administration des ports, si la volonté était bien au départ de centraliser, la pratique put amener à quelques aménagements. Les sources, lacunaires, laissent en fait l'image d'une dynastie sans modèle ou règle véritable d'administration de ces ports pourtant si stratégiques. Tout fut affaire de contexte, d'individus, et il semble presque impossible d'établir une loi générale. Nombre de cas de figures se présentent ainsi dans les textes. Dans les années 990 les documents signalent dans certains ports ce qui apparaît comme une administration bicéphale aux mains d'un cadi et d'un gouverneur. Ainsi, Yahyā Ibn Sā'id (m. 1066) mentionne pour l'année 993-994 le cadi de Tripoli 'Alī b. Haydara qui se distingua en soulevant la population contre un gouverneur félon. En 1008-1009, ce même cadi apparaît toujours chez Yahyā Ibn Sāiid mais il semble monté en grade car il est alors chargé de « la surveillance de Tripoli et de toutes les forteresses ${ }^{66}$. Au moins deux noms de gouverneurs apparaissent durant le temps où 'Alī b. Haydara demeura en fonction avant d'être décapité ${ }^{67}$. La relation des événements d'Alep donne toujours une part plus active au cadi. Ce dernier semble donc avoir dirigé l'opération et essuyé les conséquences de ses actions. Yahyā Ibn Sā'id décrit le cadi de Tripoli comme une sorte de général en chef sous l'autorité duquel se plaçaient les gouverneurs des autres cités littorales lorsque cela était nécessaire ${ }^{68}$. Quelques textes viennent cependant contredire cette affirmation. Ce fut en effet un général envoyé depuis l'Égypte qui ordonna à 'Alī b. Haydara et au gouverneur de Sayda, Ibn al-Šayh, d'expédier des navires lorsque Tyr se révolta en $998^{69}$. Le calme revenu, ce fut ensuite un des généraux arrivés d'Égypte avec des esclaves qui fut nommé gouverneur militaire de $\mathrm{Tyr}^{70}$. Si cette évocation témoigne bien du souci de centralisation déjà évoqué, elle montre également qu'en aucun cas le cadi de Tripoli n'avait une quelconque préséance sur les autres gouverneurs des villes côtières, à ce moment là au moins, et que s'il exerça véritablement un rôle de supervi-

66. Yahyā Ibn Sa'îd, Ta’rīh al-Anțākì, op. cit., p. 316 : « Mustawalī ‘alā al-naẓir fī Ṭrablūs wa fī sā’ir al-ḥuṣūn ». Le cadi étant un juge religieux, il est donc étrange de confier la direction militaire d'une zone aussi stratégique à quelqu'un qui a priori n'avait pas la formation militaire pour l'assurer correctement.

67. Ancien gouverneur de Damas, Ibn Nazāl fit allégeance aux Byzantins qui menaçaient Tripoli. Le cadi se distingua en soulevant la population de Tripoli pour chasser le traître et sa famille qui se proposaient de livrer la ville. Yahyā Ibn Sa'īid, Ta'rīh al-Antākī, op.cit., p. 229.

68. C'est en tous cas l'opinion de Bianquis, Damas et la Syrie, op. cit., vol. 1, p. 150.

69. Voir supra, note 31.

70. Yahyyā Ibn Sa'īd, Ta'rīh al-Anțākī, op.cit., p. 240-241 ; Ibn al-Qalānisī, Dayl, op. cit., p. 50 ; Nuwayrī, Nihāyat, op. cit., p. 173-174 ; Maqrīzī, 'Itti'āz, op. cit., II, p. 18-19 ; Bianquis, Damas et la Syrie, op. cit., p. 235-237. 
seur, de général en chef lors d'opérations communes, ce ne fut qu'après 998. Il faut néanmoins indiquer qu'aucun texte ne signale clairement ce fait. Ainsi, le terme de «forteresses » employé ici désignerait peut-être davantage les autres places fortes situées à l'intérieur, sous la dépendance de Tripoli, plutôt que les cités côtières ${ }^{71}$.

Il semble difficile d'affirmer que ce mode d'administration particulier que représentait l'utilisation de deux hommes, un cadi et un gouverneur militaire, ait existé ailleurs qu'à Tripoli. On sait qu'à Alep, les Fatimides nommèrent un gouverneur pour l'imposante forteresse et un autre pour la cité, mais les villes côtières étaient loin d'avoir les dimensions d'Alep ${ }^{72}$. Quelques passages donnent pourtant à penser que ce système fut adopté dans d'autres cités. Ainsi à Sayda, les Fatimides laissèrent en place un gouverneur, Ibn al-Šayh, qui était déjà là en 969 et qui était toujours à la tête de la ville lors de la révolte de Tyr en 998. Il dut décéder très peu de temps après cette date car les sources ne le mentionnent pas ensuite. Le fait que les Fatimides se soient adressés à lui pour envoyer des navires tendrait à prouver qu'il était celui qui exerçait l'autorité militaire dans la ville de Sayda et que les Fatimides n'avaient donc pas placé un de leurs fidèles pour contrôler directement la ville. Ibn al-Šayh avait dû donner suffisamment de gages de fidélité, et certainement d'argent tiré de la perception des taxes sur le commerce, pour que les califes ne jugent pas nécessaire de l'évincer. On peut néanmoins supposer qu'un cadi rendant donc la justice au nom des Fatimides et appliquant sans doute les règles du droit shiite, exerçait dans la cité. Après la mort du vieux gouverneur, la situation changea sans doute car la ville, ainsi que celles de Beyrouth et de Tyr, firent partie d'un échange entre les Fatimides et un certain Fath, maître de la citadelle d'Alep tant convoitée par les Fatimides. Ainsi, vers l'année 1016, les trois ports furent donnés en iqtă à à Fath, jusqu'à la fin de ses jours précisent les textes. Yahyā Ibn Sa'îd, contemporain des événements, laisse un récit dans lequel Fath est cité comme gouverneur de Tyr et sans doute des deux autres cités qui lui avaient été confiées, au moins jusqu'en 1024. L'auteur indique en effet que durant ces années il s'appauvrit et « fut transféré au gouvernement de Jérusalem et on lui retira Tyr, Sayda et Beyrouth $»^{73}$. Il mentionne en substance que durant tout le temps où il résida à Tyr il fut dans l'obligation de vendre peu à peu ses biens afin de payer les troupes. On sait par ailleurs

71. Il faut cependant admettre, à la suite de Thierry Bianquis, que les Fatimides paraissent avoir été pragmatiques en terme d'administration de ces zones et il se peut tout à fait qu'à certains moments le cadi de Tripoli ait exercé une sorte de préséance sur les autres gouverneurs des villes côtières. Bianquis, Damas et la Syrie, op. cit., p. 150.

72. S. Zakkar, The Emirate of Aleppo, Beyrouth, 1971, p. 64.

73. Yahyā Ibn Sa'īd, Ta'rīh al-Anțākī, op.cit., p. 326. 
qu'il fit cadeau au calife de la somme de trois cent ou de cinq cent mille dinars dès son arrivée à Tyr, somme qu'il avait dû prendre du trésor qui se trouvait dans la citadelle d'Alep et que les Fatimides lui avaient permis d'emporter $^{74}$. Les documents indiquent ainsi clairement qu'il était donc du devoir des gouverneurs de payer les troupes chargées de protéger la ville avec les taxes perçues sur les marchands. Charge au gouverneur de prélever ensuite assez de taxes pour rentrer dans ses frais, la troupe étant à sa disposition pour aider les plus récalcitrants à payer. L'épisode de Fath à la tête de trois cités côtières n'est pas isolé car quelques années plus tard, en 1058, alors que le calife al-Mustanșir préparait la prise de Bagdad par le général turc al-Basāsīrī, il confia à Timāl b. Sālih, alors maître d'Alep et pourtant peu fidèle à la dynastie égyptienne, les ports de Jubayl, Beyrouth et Acre (ou Acre, Césarée et Sayda) contre Alep, ville stratégique pour le contrôle de l'Iraq abbasside ${ }^{75}$. Un gouverneur pouvait donc exercer le contrôle sur une ou plusieurs villes à la fois. Soit les Fatimides nommaient un seul homme, qui exerçait à la fois la fonction de gouverneur civil et était le chef des troupes basées dans la ville, soit ils nommaient ou plutôt vendaient la charge de gouverneur civil à un homme à la bourse bien garnie - mais il devait y avoir un général envoyé depuis l'Égypte pour diriger les troupes. On ne peut imaginer par exemple la ville de Sayda à l'époque de Fath sans un général chargé de défendre la ville tandis que le gouverneur civil résidait à Tyr. Parfois encore, il semble que les maîtres du Caire aient nommé ou même sans doute vendu la charge de cadi d'une cité portuaire, alors qu'il s'y trouvait un gouverneur militaire chargé de la troupe et de l'ordre dans la ville, comme ce fut sans doute le cas à Tripoli et peut-être aussi à Tyr à partir des années 1040. Les sources y signalent en effet un riche et puissant cadi nommé Ibn Abī 'Aqīl (m. 1073) ${ }^{76}$. Les textes ne mentionnent cependant pas clairement de gouverneur militaire fatimide à Tyr à cette période. On sait par ailleurs que lorsque la saison de la navigation venait,

74. Yahyyā Ibn Sa'īd, Ta'rīh al-Anțākī, op. cit., p. 326 ; Ibn al-'Adīm, Zubdat al-ḥalab, op. cit., p. 213-216 ; Sibț Ibn al-Ğawzī, Mar'āt al-Zamān, éd. J. Rassi, Damas, 2005, p. 95. Rappelons qu'à cette date la dynastie avait un grand besoin de numéraire afin de compenser les fortes sommes dépensées pour payer les troupes chargées de mater la révolte d'Abū Rakwa.

75. Ibn Muyassar, Ahbār Mișr, op. cit., p. 15-16 ; Ibn al-Qalānisī, Dayl, op. cit., p. 86 ; Ibn al'Adīm, Zubdat al-ḥalab, op. cit., I, p. 273-274 ; Sibṭ Ibn al-Ğawzī, Mar'āt al-Zamān, trad. des années 447 à 452, K. Yazbeck, Traduction annotée d'un fragment de Mir'āt al-zamān de Sibț ibn al-Ğawzī : partie relative aux années 447 à 452, thèse de $3^{\mathrm{e}}$ cycle, sous la dir. de D. Sourdel, Université Paris IV, 1981 (inédite), p. 139 ; Maqrīzī, 'Itti'āz, op. cit., II, p. 235.

76. Ce cadi est connu à la fois par les chroniqueurs ou les voyageurs ainsi que par les lettres de la Geniza, qui le citent à plusieurs reprises comme grand armateur. Nāṣir-ī Husraw, Sefer Nameh, op. cit., p. 46. Goitein, A Mediterranean Society, op. cit., I, 1967, p. 293 ; Ibid., II, 1971, p. 613. Gil, Palestine, op. cit., p. 249-250, 418-419. 
vers le mois d'avril, des troupes étaient envoyées d'Égypte à destination des villes côtières de Syrie et de Palestine afin de renforcer leurs garnisons permanentes dont il apparaît qu'elles furent souvent réduites à peu de chose $^{77}$. Il existait en effet dans la plupart des villes côtières des milices armées composées de tous ceux qui voulaient prendre part au jihad. Les textes signalent de manière récurrente des heurts entre les troupes régulières fatimides et ceux qui peuvent apparaître comme des supplétifs mais qui se révélèrent souvent être des fauteurs de troubles, voire de véritables rebelles à l'ordre fatimide.

Ces miliciens, bras armés de potentats locaux désireux de prendre du large par rapport au pouvoir central, contribuèrent largement à affaiblir le réseau portuaire fatimide qui ne fut le plus souvent réduit qu'à peu de chose.

\section{Vers l'autonomie du réseau \\ ou le développement de tendances centrifuges}

La volonté de centralisation affichée par les sources s'appuyant sur des textes issus de l'administration fatimide occulte la réalité. Les Fatimides ne purent jamais exercer un véritable contrôle sur l'ensemble des ports de leur réseau. Le règne des Fatimides est marqué par la naissance et le développement de mouvements centrifuges qui se manifestèrent avec une ardeur particulière dans les ports. Ainsi, le réseau portuaire fatimide apparaît comme relativement peu fiable, et donc peu opérationnel, tant les mouvements de révoltes anti-fatimides furent nombreux à s'y manifester. Les Fatimides n'eurent souvent pas d'autres choix que de s'adapter.

L'histoire des villes portuaires sous domination fatimide est émaillée de nombreuses révoltes. Il apparaît en effet que les villes littorales égyptiennes ou syro-palestiniennes furent revêches à l'autorité centrale du Caire et profitèrent souvent d'un affaiblissement de la dynastie pour tenter de prendre leur indépendance. Les récits de la conquête fatimide de l'Égypte mettent en évidence les nombreuses révoltes qui éclatèrent à Alexandrie ou encore Tinnīs dans les années qui suivirent l'arrivée des Fatimides. Les troubles suscités par les tribus bédouines de Palestine et de Syrie dans les années 1020, les années de la guerre civile égyptienne (1065-1072) puis les derniers temps du règne des Fatimides révèlent que les cités côtières d'Égypte et du Šăm servirent souvent de refuge à des rebelles qui avaient le soutien des populations locales hostiles à un contrôle trop strict ${ }^{78}$. Dès 973974 une partie des habitants de Tinnīs se souleva et les troupes envoyées

77. Musabbiḥ̄, Tome quarantième, op. cit., p. 54. Pellat, Cinq calendriers, op. cit., p. 52.

78. Ibn Muyassar, Ahbār Mișr, op. cit., p. 46-47, 62. 
ne reprirent le contrôle de la ville que par l'intermédiaire des artisans chrétiens de la ville ${ }^{79}$. La cité d'Alexandrie se souleva également à plusieurs reprises contre la mainmise fatimide. Les gouverneurs qui y étaient nommés profitèrent des sentiments anti-shiites d'une partie de la population pour rejeter la tutelle fatimide. Entre 969 et 1171, la cité portuaire accueillit de nombreux ferments de révolte avec les docteurs de la loi (fuqahä) shaféites et à travers les madrasas sunnites qui s'y développèrent ${ }^{80}$. Sous al-Hākim, les marins et les lanceurs de naphte en poste à Alexandrie réussirent à soulever la ville ${ }^{81}$. Dès 1074, Badr al-Ğamālī dut assiéger Damiette et Alexandrie qui s'étaient soulevées ${ }^{82}$. En 1085, un fils de Badr s'y rebella avec le soutien de la population locale ${ }^{83}$. Juste après la mort d'al-Mustanșir et de Badr al-Ğamālī, al-Afḍal dut assiéger la ville plusieurs mois car le gouverneur, Nașr al-Dawla Alftakin, avait accueilli Niẓar, un des prétendants au titre de calife, écarté du pouvoir par al-Afḍal au profit d'al-Musta'alī. Finalement la ville fut reprise quand les provisions, le bois et la nourriture furent épuisés. Al-Afḍal fit conduire les rebelles au Caire tandis qu'il demeurait à Alexandrie où il nomma un cadi et un gouverneur ${ }^{84}$. Enfin, dans les dernières années de la dynastie, la cité fut considérée comme le lieu idéal pour qui voulait recruter des hommes susceptibles de faire le coup de main contre le vizir en place $^{85}$. On comprend ainsi mieux ce qui poussa les califes à ne pas octroyer à la ville trop de capacités navales susceptibles de renforcer un peu plus les possibles rebelles et de rendre la reprise de contrôle plus difficile.

Plus éloignées encore de la capitale politique, les cités portuaires syropalestiniennes ne furent pas en reste. La fin du $x^{e}$ siècle constitua une période de soulèvement pour plusieurs d'entre elles ${ }^{86}$. En 997-998, Tyr connut une révolte populaire qui s'inscrit dans le contexte d'une hausse du prix des denrées alimentaires, ce qui en ferait ainsi une révolte à prétention sociale ${ }^{87}$. Le refus de la mainmise maghrébine sur la région

79. Ibn al-Muqaffā', Histoire des patriarches, op. cit., éd. p. 89, tr. p. 132 ; Maqrīzī', 'Itti '‘̄à, op. cit., I, p. 180, 182.

80. G. Leiser, "The Madrasa and the Islamization of the Middle East : The Case of Egypt », Journal of the American Research Center in Egypt 22, 1985, p. 29-47.

81. Maqrīzī', 'Itti' āz, op. cit., I, p. 312-313.

82. Ibn Muyassar, Ahbār Mișr, op. cit., p. 41.

83. Ibid., p. 46-47.

84. Ibid., p. 62 ; Nuwayrī, Nihāyat, op. cit., p. 244-245 ; Maqrīzī, 'Itti'āz, op. cit., p. 282.

85. Cl. Cahen, « Un récit inédit du vizirat de Dirgham », Annales Islamologiques VIII, 1969, p. 27-46. Ibn Munqid, Kitāb al-'I'tibār. Des enseignements de la vie, Souvenirs d'un gentilhomme syrien du temps des Croisades, éd. et tr. fr. A. Miquel, Paris, 1983, éd. p. 351, tr. p. 123.

86. Maqrīzī', 'Itti' āz, op. cit., p. 45-48.

87. C'est en tout cas l'avis de E. Ashtor, « Républiques urbaines dans le Proche Orient à l'époque des Croisades », Cahiers de Civilisations Médiévales 18, 1975, p. 117-128. 
correspondrait peut-être mieux au véritable point de départ de cette révolte menée par un marin, 'Allāqa al-Bahrī, qui fit massacrer le contingent berbère placé là par les Fatimides et en appela même aux Byzantins qui s'approchèrent de la cité mais furent défaits par la flotte égyptienne qui croisait dans la zone ${ }^{88}$. Les Fatimides récupèrent la ville mais le sentiment anti-maghrébin resta vivace dans la population locale ${ }^{89}$. Dans la seconde moitié du XI ${ }^{\mathrm{e}}$ siècle débuta une nouvelle phase de révoltes. Celles-ci correspondent à l'affaiblissement du califat et à la montée en puissance des Seldjoukides dans la province du Šām. Compte tenu de l'importance de ces villes sur le plan militaire et commercial, la réaction fatimide à la révolte de Tripoli et de Tyr fut rapide. Badr reprit le contrôle de Tripoli, mais échoua à Tyr qui demeura quasi indépendante pendant vingt ans. Durant cette période, les textes montrent que Ibn Abī 'Aqīl (m. 1073) puis ses fils qui lui succédèrent à la tête de la ville versaient un tribut aux Seljoukides, dont les troupes empêchèrent à plusieurs reprises les armées fatimides de poursuivre le siège de la ville ${ }^{90}$. Un texte indique même qu'il existait un pacte de non agression entre la ville et les Seljoukides ${ }^{91}$. Tyr, comme les autres villes littorales de la région syrienne, se trouvait au contact de deux périphéries. Le moment s'avérait donc propice pour les élites urbaines de toutes confessions et écoles juridiques de tenter de jouer sur les deux tableaux afin de conquérir leur autonomie. En 1089, les Fatimides reprirent la ville, ils y placèrent un gouverneur qui se révolta assez vite. Un document rédigé par Evyātār ha-Kohen, membre de la communauté juive de Tyr et présent dans la ville durant ces années, indique que le gouverneur nommé par les Fatimides, Munīr (ou Nașīr) al-Dawla al-Ğuyūš̄i, se révolta dès 1090 et que la situation fut reprise en main par les Fatimides en $1093^{92}$. La documentation arabe, quant à elle, indique en substance que la révolte éclata en l'année 486 de l'hégire, cette année débutant en février 1093, et la ville fut reprise le 12 juillet $1093^{93}$. Al-Katîla, le gouverneur nommé à la tête de Tyr, rejeta à son tour la tutelle fatimide en $1096^{94}$. À partir de cette date et jusqu'à la prise de Tyr par les

88. Yahyā Ibn Sa'īid, Ta’rīh al-Anțākī, op.cit., p. 230-232 ; Ibn al-Qalānisī, Dayl, op. cit., p. 50-51. 89. Ibn al-Qalānisī, Dayl, op. cit., p. 50-51. Bianquis, Damas et la Syrie, op. cit., I, p. 236.

90. Ibn al-Qalānisī, Dayl, op. cit., p. 98 ; Ibn Muyassar, Ahbār Miṣr, op. cit., p. 37 ; Al-Maqrīzī, 'Itti'āz, op. cit., II, p. 303.

91. Sibț Ibn al-Ğawzī, Mirā’t al-zamān, éd. A. Sawīm, Ankara, 1968 p. 178.

92. M. Gil, " Megillat Evyātār», Perāqīm be-tōledōt yerūshālayim bìmē ha-beynayìm, éd. B. Z. Kedar, Jérusalem, 1979, p. 62.

93. Ibn al-Qalānisī, Dayl, op. cit., p. 124-125 ; Ahbār Miṣr, op. cit., p. 51 ; Maqrīzī, 'Itti'āza, op. cit., II, p. 328.

94. Ibn al-Qalānisī, Dayl, op. cit., p. 96-98, 124, 133 ; Ibn al-Ațīr, Kāmil, op. cit., X, p. 40-42. 
Croisés en 1124, la cité n'obéit plus que de manière très relative au pouvoir égyptien. En accord avec le Caire, le gouverneur fatimide de la ville donna même son autorisation pour que l'atâbeg de Damas envoie un général et des troupes pour protéger la ville alors que la prière se faisait toujours au nom des Fatimides et que la monnaie demeurait celle des Fatimides ${ }^{95}$.

Les bourgeoisies commerçantes des cités côtières du Šām, enrichies grâce à la sécurité des routes commerciales garanties par les Fatimides voulaient changer de protecteurs ${ }^{96}$. Aux XI ${ }^{\mathrm{e}}$ et XII ${ }^{\mathrm{e}}$ siècles, les documents de la Geniza témoignent que Tyr, Tripoli et la plupart des ports de la côte étaient fréquentés par des marchands venant de toutes les régions de la Méditerrané $e^{97}$. Les quais des ports syro-palestiniens étaient encombrés de marchandises destinées le plus souvent à l'Égypte ${ }^{98}$. Les bourgeoisies urbaines impliquées dans le commerce maritime au long cours avaient choisi de soutenir la dynastie fatimide à la fin du $\mathrm{x}^{\mathrm{e}}$ siècle et au début du $\mathrm{XI}^{\mathrm{e}}$ siècle : grâce à sa flotte, celle-ci pouvait assurer la sécurité des routes commerciales menacées par les Byzantins tout proches.

Les réformes militaires et la conjoncture obligèrent peu à peu les Fatimides à accorder davantage d'autonomie aux différents responsables locaux. Très rapidement, sans doute dès le règne du calife al-'Azīz (975996) qui procéda à une réforme de l'armée, la dynastie dut trouver de plus en plus de numéraire. Tout laisse à penser qu'al-Hākim, peut-être d'abord pour les villes côtières de Syrie seulement, décida d'affermer la charge de gouverneur civil à des hommes qui devaient verser une somme correspondant aux rendements annuels estimés des villes. Ces hommes pouvaient ensuite lever les taxes qu'ils voulaient pour leur propre compte de manière à rentrer dans leur frais. À Tyr, le cadi Ibn Abī 'Aqīl autorisait les marchands qui lui confiaient leurs biens, à ne pas payer certaines taxes, à condition toutefois qu'ils aient résidé dans son caravansérail (hāan). Cette autonomie était justement permise par le fait que le cadi avait sans aucun doute, comme Fath al-Qal'î avant lui, payé aux Fatimides la somme correspondant au montant estimé des taxes annuelles. Il se débrouillait ensuite comme il l'entendait pour récupérer sa mise de départ plus de substantiels bénéfices. Il ne s'agissait donc pas d'une méthode ponctuelle de gestion des villes côtières mais cela paraît davantage procéder d'une

95. Ibn al-Qalānisī, Dayl, op. cit., p. 133, 182, 211.

96. Ashtor, « Républiques urbaines », art. cit., p. 117-128.

97. S. D. Goitein, Letters of Medieval Jewish Traders, Princeton, 1973, p. 45-48, 89-94 ; Nāṣir-ī Husraw, Sefer Nameh, op. cit., p. 41.

98. J. Braslawi, «Qeta'ī Genizah ‘al-'Irei ha-hōf 'Ako ve-G'bel », Erets Israel 1, 1951, p. 153157 (en hébreu). E. Strauss-Ashtor, « Te‘ūdōt le-ḥeqer ha-Yisțōriah ha-kalkalīt ve ha-ḥevratīt shel ha-yehūdīm be-mizrah ha-qarōv », Zion 7, 1941-42, p. 142-155 (en hébreu). 
méthode structurelle. Ibn Abī 'Aqīl fit simplement preuve de plus d'habileté que Fath dans la gestion de la ville et de ses biens. Peu à peu, en fait, sans doute au fur et à mesure que les besoins en numéraire grandissaient et que leur pouvoir s'affaiblissait, les Fatimides laissèrent s'installer des dynasties de gouverneurs civils ou de cadis. À Tripoli, les Banū 'Ammār, à Tyr, les Banū 'Aqīl dont les membres furent nommés à de hautes fonctions dans plusieurs villes de la côte, mais aussi à Alep ${ }^{99}$. Ces hommes étaient très liés au commerce maritime. Ainsi, outre le hāān qu'il possédait, le cadi Ibn Abī 'Aqīl était un grand commerçant ainsi qu'un armateur qui louait ses vaisseaux. À Tripoli, une personnalité semblable se dégage en la personne de Amīn al-Dawla Abū Ṭālib Ibn 'Ammār. Lui aussi fut cadi de la ville et un armateur dont les lettres de la Geniza ont gardé la trace ${ }^{100}$.

À la veille des croisades, les Fatimides ne géraient plus directement la plupart des villes portuaires de Syrie-Palestine. La stratégie fatimide, surtout à la mort d'al-Mustanșir et de Badr al-Ğamālī paraît avoir négligé la mainmise directe sur les cités du Šâm au profit d'une reconnaissance théorique moins coûteuse militairement et financièrement. La menace exercée par les marines européennes sur les ports du Šām à partir de 11091110 fit comprendre aux bourgeoisies urbaines locales que la marine fatimide restait la meilleure défense. Cependant, les tergiversations du vizir al-Afḍal pour aller aider Tripoli assiégée semblaient indiquer que les ports du Šām n'étaient plus considérés comme des priorités absolues. Les ports égyptiens et surtout la liberté de commerce dans la mer Rouge paraissaient désormais plus essentiels. L'organisation navale fatimide très centralisée en Égypte ne favorisait pas les actions rapides que nécessitaient les sièges que les Croisés faisaient subir aux cités portuaires. Les sièges duraient en moyenne un peu moins de six semaines alors qu'il fallait souvent environ deux mois à une flotte fatimide pour parvenir sur site ${ }^{101}$. La perte de la quasi-totalité des ports du Šām en 1124, après le passage de Tyr aux mains des croisés, ne provoqua d'ailleurs pas un arrêt immédiat des actions navales fatimides. Les sources mentionnent au contraire une hyperactivité navale fatimide à partir de l'Égypte vers les ports qui étaient devenus chrétiens.

99. Bianquis, Damas et la Syrie, op. cit., 2, p. 566.

100. Goitein, Letters, op. cit., p. 158; Id., Mediterranean Society, op. cit., I, p. 315, 479, n. 14.

101. W. Hamblin, «The Fatimid Navy during the Early Crusades : 1099-1124 », The American Neptune 46, 1986, p. 77-83. 


\section{Conclusion}

Les Fatimides n'utilisèrent jamais réellement les potentialités stratégiques que leur offrait leur réseau portuaire. La difficulté que la dynastie éprouva assez vite à maîtriser les ports en question, l'objectif politique situé loin de la mer, rien en fait n'incitait la dynastie égyptienne à organiser les ports sous son contrôle en un réseau efficace d'un point de vue naval. Le réseau portuaire fatimide apparaît très largement comme un réseau simple, c'est-à-dire dans lequel aucun des éléments intermédiaires, les ports égyptiens ou syriens, n'entretint vraiment de relations militaires autres qu'avec le centre du réseau. Ce modèle d'organisation, extrêmement centralisé, s'il niait apparemment les avantages maritimes que pouvaient apporter la maîtrise de littoraux sur lesquels étaient réparties les villes portuaires, peut être considéré comme une véritable erreur stratégique. Tout le paradoxe est pourtant là. En effet, en ne développant pas ce réseau, en centralisant à ce point les sites de stationnement des flottes fatimides et de construction navale si loin de la mer, la dynastie égyptienne ne souffrit qu'assez peu de la perte d'un de ses ports de la côte syrienne. De plus, au moment des croisades, l'essentiel de l'économie fatimide était tourné vers l'océan Indien, inaccessible aux croisés, et ne reposait plus réellement sur les ports du Šàm. Seule la destruction du gros de la flotte fatimide stationnée devant Ascalon en 1123, et non pas en Égypte comme elle en avait l'habitude, constitua une exception à la règle de la centralisation. Aucun des ports n'ayant constitué une véritable base navale pour les Fatimides, la portée de la perte de ces villes, si elle porta un coup dur à la dynastie, fut en définitive plus idéologique que navale ${ }^{102}$.

102. J. H. Pryor, Geography, technology and war, Cambridge, 1992 p. 116-119 ; Id., «Water, Water Everywhere, Nor any Drop to Drink. Water Supplies for the Fleets of the First Crusade », Dei gesta per Francos. Études sur les croisades dédiées à Jean Richard, éd. M. Balard, B. Z. Kedar, J. Riley-Smith, Aldershot, 2001, p. 21-28. John H. Pryor considère que la perte des ports syro-palestiniens fut une catastrophe pour la marine fatimide car cela réduisait les possibilités de faire de l'eau douce et donc diminuait d'autant le champ d'action de la flotte fatimide. Il faut pourtant constater qu'après la perte de Tyr en 1124 et même d'Ascalon en 1153, la marine fatimide fut toujours active sur les côtes désormais croisées. Sur toutes les expéditions navales fatimides après 1124, voir Foucher de Chartres, Historia Hierosolimitana, Recueil des Historiens des croisades, Historiens occidentaux, III, Paris, 1866, p. 459-466 ; Guillaume de Tyr, Historia rerum in partibus transmarinis gestarum, Ibid., I, Paris, 1844, p. 558-576, 587-588 ; Ibn Muyassar, Ahbār Mișr, op. cit., p. 96 ; Maqrīzī, 'Itti'āz, op. cit., III, p. 102, 161, 202, 224, 230, 233, 236, 283, 320. 
2. Bramoulle?:Mise en page 1 23/03/10 14:30 Page 74

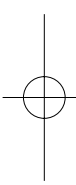

